\title{
Resposta hemática de tilápias-do-nilo alimentadas com dietas suplementadas com colina e submetidas a estímulo por baixa temperatura
}

\author{
Ademir Calvo Fernandes Junior ${ }^{1}$, Luiz Edivaldo Pezzato ${ }^{2}$, Igo Gomes Guimarães ${ }^{1}$, Caroline \\ Pelegrina Teixeira ${ }^{1}$, João Fernando Albers Koch ${ }^{1}$, Margarida Maria Barros ${ }^{2}$
}

${ }^{1}$ Laboratório de Nutrição e Saúde de Peixes - AquaNutri, UNESP, Botucatu, São Paulo, Brasil.

2 Departamento de Melhoramento e Nutrição Animal, UNESP, Fazenda Lageado, Botucatu, São Paulo, Brasil.

RESUMO - Esta pesquisa foi realizada com o objetivo de avaliar a resposta hemática de tilápias-do-nilo (Oreochromis niloticus) arraçoadas com dietas suplementadas com colina e submetidas a estímulo por baixa temperatura. O período experimental foi realizado em duas etapas: a primeira, de 109 dias, e a segunda, de 7 dias. Durante a primeira etapa, foram utilizados 192 alevinos com peso médio inicial de 4 g, distribuídos em 32 tanques-rede de $200 \mathrm{~L}$ instalados em aquários de mil litros. As rações foram formuladas de modo a apresentar 28,0\% de proteína digestível e 3.100,0 kcal ED/kg e mesma concentração de aminoácidos. O delineamento experimental foi inteiramente casualizado com oito tratamentos e quatro repetições. As rações foram suplementadas com colina (cloreto de colina 60,0\%), de modo a apresentar 100,0; 200,0; 400,0; 600,0; 800,0; 1.000,0 e 1.200,0 mg/kg de ração, e avaliadas em comparação a uma ração sem suplementação. Após o período de 109 dias, foram efetuadas as análises hematológicas dos peixes. Após as análises, os peixes foram transferidos para a sala de desafio e distribuídos em 24 aquários, onde foram mantidos a $17^{\circ} \mathrm{C}$ durante sete dias. Após esse período, foram feitas as mesmas análises do período anterior ao desafio. A suplementação de colina não influenciou a eritropoiese ao estímulo pelo frio. A suplementação dietética de colina não interfere na síntese de eritrócitos e leucócitos e a temperatura de $17,0^{\circ} \mathrm{C}$ determina linfopenia e neutrofilia.

Palavras-chave: cloreto de colina, estresse, hematologia, nutrição de peixes, temperatura

\section{Hematic response of Nile tilapia fed diets supplemented with choline and submitted to stimulus by low temperature}

\begin{abstract}
The aim of this study was to evaluate the hematic response of Nile tilapia (Oreochromis niloticus) fed diets supplemented with choline and submitted to temperature stress. The experimental period was realized in two phases: the first, during 109 days, and the second, for seven days. During the first stage, 192 fingerlings with average initial weight of $4 \mathrm{~g}$ were distributed in 32 net cages $(200 \mathrm{~L}$ ) allocated in 1,000-L aquaria. The diets were formulated to present $28 \%$ of digestible protein and $3,100 \mathrm{kcal} \mathrm{DE} / \mathrm{kg}$ and the same concentration of amino acids. It was used a complete random experimental design with eight treatments and four replicates. The diets were choline supplemented (60\% choline chloride) in order to present $100.0 ; 200.0 ; 400.0 ; 600.0 ; 800.0 ; 1,000.0$ and $1,200.0 \mathrm{mg} / \mathrm{kg}$ of diet and evaluated by comparing to a non-supplemented diet. After the 109-day period, the hematological analyses of the fish were performed. After these analyzes, fish were transferred to the challenge room, distributed in 24 aquaria, and kept at $17^{\circ} \mathrm{C}$ during seven days. After this period, the same analyzes of the period previous to the challenge were done. Choline supplementation did not affected erythropoiesis to stimulus by the cold temperature. Dietary choline supplementation does not affect erythrocyte and leukocyte synthesis and the $17^{\circ} \mathrm{C}$ temperature determines lymphopenia and neutrophilia.
\end{abstract}

Key Words: choline chloride, fish nutrition, hematology, stress, temperature

\section{Introdução}

A nutrição tem como principal objetivo determinar as exigências nutricionais dos peixes nas diferentes fases de vida. Nutrientes como vitaminas, minerais, proteínas e gorduras são essenciais para o desenvolvimento animal, em proporções adequadas, de forma a atender as necessidades nutricionais do peixe, visando ao seu maior potencial de crescimento e à manutenção da saúde.

Entre as vitaminas, a colina possui grande importância, sendo essencial para o desenvolvimento dos animais. É responsável pela manutenção das células estruturais, do transporte de lipídeos e da síntese de metionina (aminoácido 
limitante para os animais) (Devlin, 2000; Halver, 1989). Além disso, alguns trabalhos com outras espécies mostram que a colina é importante para a manutenção de células vermelhas, principalmente quando os animais sofrem algum estresse.

A hematologia é bastante utilizada para se avaliar o estado de saúde animal por intermédio de análise sanguínea. O sangue é um tecido líquido, móvel, do tipo conjuntivo, que está em equilíbrio com praticamente todos os outros tecidos, constituindo uma das grandes forças homeostáticas do organismo. Este distribui calor, transporta gases respiratórios, nutrientes e produtos de excreção, além de atuar na defesa do organismo. O volume de sangue dos peixes (sem estresse) é em torno de 1,5 a $3,0 \%$ do peso vivo em teleósteos e cerca de 6,0\% nos elasmobrânquios (Ranzani-Paiva \& Silva-Souza, 2004).

Diferentemente dos mamíferos, os peixes têm vários centros hematopoiéticos (rim cefálico, baço, fígado, entre outros). Caso uma enfermidade comprometa o principal centro hematopoiético, outros órgãos podem assumir a produção de células. Assim, fica difícil a caracterização do quadro leucocitário dos peixes com lesão dos órgãos (Feldman et al., 2000).

O sangue é composto por três camadas: líquida (soro ou plasma), branca (leucócitos e trombócitos) e vermelha (eritrócitos). A fase líquida plasma é composta de 90,0\% de água, 7,0\% de proteínas (globulinas e albuminas) e $3,0 \%$ de solutos variados eletrólitos. Tem como função o transporte de substâncias, anticorpos produzidos pelos plasmócitos e regulação osmótica entre o sangue e o líquido tecidual. A fase sólida é composta por elementos figurados, como os glóbulos vermelhos (eritrócitos) e os glóbulos brancos (linfócitos, monócitos, neutrófilos, basófilos, eosinófilos, célula granulocítica especial e trombócitos) (Feldman et al., 2000).

Sabendo da importância da hematologia como ferramenta de aplicação, esta pesquisa teve por finalidade avaliar a suplementação de níveis de colina para tilápiado-nilo, por meio da análise hematológica antes e após o estímulo pelo frio.

\section{Material e Métodos}

O presente estudo foi realizado na Universidade Estadual Paulista "Júlio de Mesquita Filho" (UNESP) - Botucatu, Faculdade de Medicina Veterinária e Zootecnia, UNESP, Universidade Estadual Paulista, Câmpus de Botucatu, DMNA, AquaNutri. Foram utilizados alevinos de tilápiado-nilo (Oreochromis niloticus), provenientes da piscicultura Aracanguá, localizada na cidade de Santo
Antônio do Aracanguá, São Paulo. Os alevinos foram inicialmente alojados em tanques circulares de $250 \mathrm{~L}$, para seleção e distribuição nos aquários experimentais, e ficaram durante duas semanas para adaptação recebendo a dieta controle isenta de colina.

Os alevinos com aproximadamente 4,0 g foram distribuídos em 32 tanques-rede com capacidade de $200 \mathrm{~L}$ e na densidade de seis peixes por tanque-rede. Esses tanques-rede ficavam em número de quatro dentro de aquários de $1000 \mathrm{~L}$, totalizando quatro repetições.

Esses aquários estavam ligados ao sistema de recirculação de água, com aquecimento controlado por sistema digital integrado, no sentido de manter a temperatura da água $\left(25,3 \pm 0,2^{\circ} \mathrm{C}\right)$. A água do sistema estava acoplada à central de aeração e filtragem físico-biológica, a qual manteve sua qualidade e possibilitou dez renovações diárias. O arraçoamento foi feito à vontade quatro vezes ao dia (8, 11, 14 e 17 h), de forma a não haver sobra excessiva nos aquários.

As dietas foram suplementadas com cloreto de colina $(60,0 \%)$, de maneira a apresentar um dos sete níveis de colina - 100,0; 200,0;400,0; 600,0;800,0; 1.000,0 e $1.200,0$ mg/kg de ração — e foram avaliadas em comparação a uma ração controle, sem suplementação de colina. Todas as dietas foram balanceadas segundo NRC (1993) e distribuídas completamente ao acaso, totalizando quatro repetições por nível de colina.

As rações foram formuladas com o intuito de apresentar 28,0\% de proteína digestível e 3.100,0 kcal ED/kg de dieta. Os níveis de aminoácidos foram balanceados segundo recomendação de Furuya et al. (2001), além de níveis iguais de fibra bruta.Foi utilizada dieta prática à base de farelo de soja, farelo de algodão 28,quirera de arroz e amido, sendo que para formulação das dietas, foram utilizados os valores nutritivos dos ingredientes obtidos por Pezzato et al.(2009), e confeccionadas objetivando-se conter os níveis preestabelecidos de colina e atender as exigências nutricionais da tilápia para os demais nutrientes (Tabela 1 ).

As rações foram extrusadas, secas em estufa de recirculação de ar forçada a $55,0^{\circ} \mathrm{C}$ por 24 horas e, quando necessário, quebradas de forma a obter grânulos condizentes ao tamanho dos peixes. As análises químicobromatológicas das rações foram realizadas no Laboratório de Bromatologia do Departamento de Melhoramento e Nutrição Animal da FMVZ, Unesp - Câmpus de Botucatu (AOAC, 1975).

Diariamente, foi aferida a temperatura da água e, semanalmente, o $\mathrm{pH}$, o teor de oxigênio dissolvido e a amônia total. Os aquários foram sifonados mensalmente 
nos dois primeiros meses e, depois de 60 dias, foram sifonados quinzenalmente, para manter a qualidade da água. Ao final de 109 dias, foram determinados o hemograma e o leucograma antes e após o estímulo pelo frio.

Para avaliação dos parâmetros hematológicos, foram retirados aleatoriamente seis peixes por tratamento dentre os tanques-rede. Os peixes primeiramente foram anestesiados com benzocaína, na concentração de 1,0 g do anestésico em $15 \mathrm{~L}$ de água, e, após a completa dessensibilização, foi coletado sangue por meio de punção do vaso caudal com auxílio de seringa de 1,0 mL, banhada com anticoagulante (EDTA 3,0\%). A contagem do número de eritrócitos e leucócitos foi realizada pelo método do hemocitômetro em câmara de Neubauer, utilizando como diluente a solução azul de toluidina a $0,01 \%$, em pipeta de Thoma. A taxa de hemoglobina (Hb) foi determinada pelo método da cianometaemoglobina utilizando-se o kit comercial Analisa Diagnóstica ${ }^{\circledR}$, para determinação colorimétrica, segundo Collier (1944). A porcentagem de hematócrito (Htc) foi determinada pelo método do microhematócrito, segundo Goldenfarb et al. (1971).

A contagem diferencial de leucócitos foi realizada por meio de extensões em lâminas. Estas foram limpas com detergente e água, desengorduradas com éter etílico PA e secas com auxílio de gaze. Devidamente identificadas, foram confeccionadas seis lâminas por tratamento e coradas com o corante May-Grunwald Giemsa utilizando técnicas descritas por Tavares-Diaz \& Moraes (2004). Para essa contagem, utilizou-se microscópio com auxilio de óleo de imersão, com aumento de 100 vezes, sendo contadas 200 células, e estabeleceu-se o percentual de cada componente celular (linfócito, neutrófilo, monócito, basófilo).

Posteriormente a essas análises, calcularam-se os índices hematimétricos: volume corpuscular médio [VCM = (Htc $\times 10)$ /eritrócitos] e concentração de hemoglobina corpuscular média [CHCM $=(\mathrm{Hb} \times \mathrm{Htc}) \times 100]$, segundo Wintrobe (1934). A proteína plasmática total foi mensurada por meio do uso de refratômetro manual de Goldberg, pela quebra do tubo de microhematócrito logo acima da camada de leucócitos, após a leitura do hematócrito (Jain, 2000).

Após as avaliações hematológicas, os peixes permaneceram na mesma estrutura com o sistema de aquecimento desligado, objetivando baixar gradativamente a temperatura para posterior mudança dos animais para a sala de desafio. A partir do momento em que a temperatura

Tabela 1 - Composição das dietas experimentais

\begin{tabular}{|c|c|c|c|c|c|c|c|c|}
\hline \multirow[t]{2}{*}{ Ingrediente } & \multicolumn{7}{|c|}{ Nível suplementação de colina (mg/kg) } & \multirow[b]{2}{*}{1200} \\
\hline & 0,00 & 100 & 200 & 400 & 600 & 800 & 1000 & \\
\hline Farelo de soja & 54,15 & 54,15 & 54,15 & 54,15 & 54,15 & 54,15 & 54,15 & 54,15 \\
\hline Farelo de algodão 28 & 9,00 & 9,00 & 9,00 & 9,00 & 9,00 & 9,00 & 9,00 & 9,00 \\
\hline Quirera de arroz & 28,00 & 28,00 & 28,00 & 28,00 & 28,00 & 28,00 & 28,00 & 28,00 \\
\hline Amido de milho & 5,00 & 4,984 & 4,968 & 4,936 & 4,904 & 4,872 & 4,84 & 4,808 \\
\hline Antioxidante - BHT & 0,02 & 0,02 & 0,02 & 0,02 & 0,02 & 0,02 & 0,02 & 0,02 \\
\hline DL-metionina & 0,18 & 0,18 & 0,18 & 0,18 & 0,18 & 0,18 & 0,18 & 0,18 \\
\hline Vitamina C polifosfatada $35 \%$ & 0,02 & 0,02 & 0,02 & 0,02 & 0,02 & 0,02 & 0,02 & 0,02 \\
\hline Cloreto de colina $60 \%$ & 0,00 & 0,016 & 0,032 & 0,064 & 0,096 & 0,128 & 0,16 & 0,192 \\
\hline Suplemento mineral/vitamínico ${ }^{1}$ & 0,41 & 0,41 & 0,41 & 0,41 & 0,41 & 0,41 & 0,41 & 0,41 \\
\hline Fosfato bicálcico & 3,12 & 3,12 & 3,12 & 3,12 & 3,12 & 3,12 & 3,12 & 3,12 \\
\hline $\mathrm{NaCl}$ & 0,10 & 0,10 & 0,10 & 0,10 & 0,10 & 0,10 & 0,10 & 0,10 \\
\hline \multicolumn{9}{|l|}{ Composição química } \\
\hline Energia digestível (kcal/kg) & 3100 & 3100 & 3100 & 3100 & 3100 & 3100 & 3100 & 3100 \\
\hline Proteína bruta (\%)* & 30,01 & 30,01 & 30,01 & 30,01 & 30,01 & 30,01 & 30,01 & 30,01 \\
\hline Proteína digestível (\%) & 28,00 & 28,00 & 28,00 & 28,00 & 28,00 & 28,00 & 28,00 & 28,00 \\
\hline Fibra bruta $(\%)^{*}$ & 8,33 & 8,33 & 8,33 & 8,33 & 8,33 & 8,33 & 8,33 & 8,33 \\
\hline Fibra bruta (\%) & 4,86 & 4,86 & 4,86 & 4,86 & 4,86 & 4,86 & 4,86 & 4,86 \\
\hline Extrato etéreo (\%)* & 0,74 & 0,74 & 0,74 & 0,74 & 0,74 & 0,74 & 0,74 & 0,74 \\
\hline Extrato etéreo (\%) & 1,14 & 1,14 & 1,14 & 1,14 & 1,14 & 1,14 & 1,14 & 1,14 \\
\hline Ca total & 1,39 & 1,39 & 1,39 & 1,39 & 1,39 & 1,39 & 1,39 & 1,39 \\
\hline Fósforo disponível & 0,49 & 0,49 & 0,49 & 0,49 & 0,49 & 0,49 & 0,49 & 0,49 \\
\hline Metionina & 0,47 & 0,47 & 0,47 & 0,47 & 0,47 & 0,47 & 0,47 & 0,47 \\
\hline Metionina + cistina & 0,81 & 0,81 & 0,81 & 0,81 & 0,81 & 0,81 & 0,81 & 0,81 \\
\hline Lisina & 1,88 & 1,88 & 1,88 & 1,88 & 1,88 & 1,88 & 1,88 & 1,88 \\
\hline Triptofano & 0,36 & 0,36 & 0,36 & 0,36 & 0,36 & 0,36 & 0,36 & 0,36 \\
\hline Treonina & 0,99 & 0,99 & 0,99 & 0,99 & 0,99 & 0,99 & 0,99 & 0,99 \\
\hline
\end{tabular}

${ }^{1}$ Suplemento vitamínico e mineral (mg/kg de dieta): vitamina A - 16.060 mg; vitamina $\mathrm{D}_{3}$ - 4.510 mg; vitamina $\mathrm{E}$ - 250 mg; vitamina $\mathrm{K}_{3}$ - 30 mg; vitamina $\mathrm{B}_{1}$ - 32 mg; vitamina $\mathrm{B}_{2}$ - $32 \mathrm{mg}$; vitamina $\mathrm{B}_{12}$ - 0,032 mg; vitamina $\mathrm{B}_{6}$ - $32 \mathrm{mg}$; vitamina C - zero; pantotenato de cálcio - $80 \mathrm{mg}$; niacina - $170 \mathrm{mg}$; ácido fólico - $10 \mathrm{mg}$; biotina - $10 \mathrm{mg}$; cloreto de colina. ${ }^{2}$ Óxido de cobalto - 0,5 mg; óxido de cobre - 20 mg; óxido de ferro - 150 mg; iodeto de cálcio - 1 mg; óxido de manganês - 50 mg; óxido de selênio - 0,7 mg; óxido de zinco - 150 mg; veículo q.s.p. - 1.000 g; *Analisado (fornecido pela Mogiana Alimentos); ${ }^{2}$ ND = não-determinado. 
da água dos aquários de ambas as estruturas experimentais estava similar, os peixes foram transferidos. A sala experimental de desafio por temperatura contém 24 aquários de $40 \mathrm{~L}$, com filtros individualizados e aeração. Foram distribuídos aleatoriamente 96 peixes, na densidade de quatro/aquário. O delineamento experimental foi o inteiramente casualizado com oito tratamentos e seis repetições, sendo cada peixe considerado uma repetição.

Após a distribuição dos peixes, a temperatura da água dos aquários foi reduzida do conforto térmico para a espécie para $17,0^{\circ} \mathrm{C}$, permanecendo nesse valor durante sete dias. Ao final do período, foram avaliados os mesmos parâmetros hematológicos do momento anterior ao estímulo, a contagem do número de eritrócitos e leucócitos, taxa de hemoglobina, porcentagem de hematócrito e proteína plasmática total. Foram, ainda, calculados os índices hematimétricos sanguíneos, volume globular médio, concentração de hemoglobina globular média.

Os dados de hematologia foram submetidos à análise de variância para o modelo de medidas repetidas em grupos independentes (Johnson \& Wichern, 2002).

\section{Resultados e Discussão}

Os parâmetros de qualidade de água, monitorados na fase I, estiveram dentro do considerado adequado para manutenção da condição de saúde dos peixes segundo Boyd (1996), com 7,15 mg/L de oxigênio dissolvido e 7,1 de $\mathrm{pH}$.

O eritrograma dos peixes na fase anterior ao estímulo a frio não foi influenciado pela suplementação de colina, com exceção da porcentagem de hematócrito dos peixes alimentados com a dieta suplementada com 200,0 mg colina/kg de ração que apresentaram valor acima da média dos peixes dos demais tratamentos. O volume corpuscular médio e a concentração de hemoglobina corpuscular média também não foram influenciados pela suplementação de colina na dieta nessa fase (Tabela 2).

Após o estímulo por baixa temperatura $\left(17,0^{\circ} \mathrm{C}\right)$, observa-se que os animais apresentaram prejuízo na síntese de células vermelhas, independentemente da suplementação de colina, e que esta foi significativamente inferior à eritropoiese em condições adequadas de temperatura. A porcentagem de células vermelhas foi inferior $(\mathrm{P}<0,05)$ na segunda fase nos peixes alimentados com ração suplementada com níveis de 100,0; 200,0 e 1.200,0 mg colina/kg de ração. Nesses mesmos animais, embora não de forma significativa, houve queda numérica na taxa de hemoglobina, no volume da célula e na concentração de hemoglobina celular. A taxa de hemoglobina foi

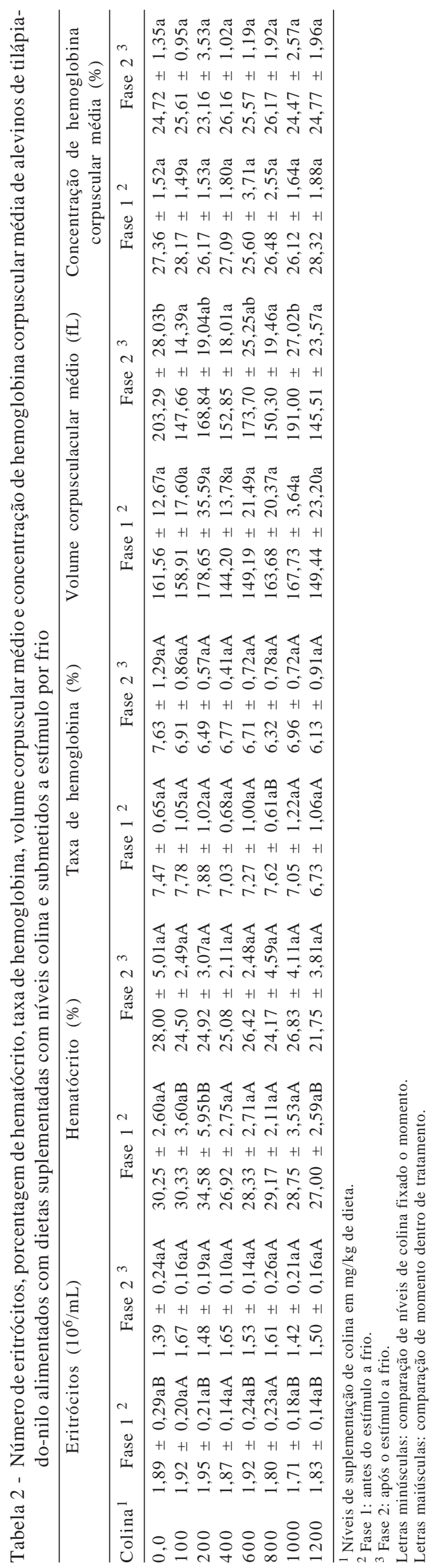

R. Bras. Zootec., v.39, n.8, p.1619-1625, 2010 
influenciada significativamente $(\mathrm{P}<0,05)$, após o estímulo a frio, nos peixes alimentados com a ração suplementada com 800,0 mg de colina/kg de ração (Tabela 2).

Igualmente à série vermelha, os valores de leucócitos, bem como da proteína plasmática total, não se alteraram em função do nível de colina suplementada na ração, nem antes e nem após o estresse (Tabela 3). No entanto, a porcentagem de linfócitos e de neutrófilos variou com o nível de suplementação após o estímulo por frio (Tabela 4). $\mathrm{O}$ estresse por temperatura determinou aumento significativo no número de neutrófilos. O volume corpuscular médio também se alterou em função do nível de colina, sendo que a ausência de suplementação e a suplementação de $1.000,0 \mathrm{mg}$ colina/kg de ração determinaram a liberação de células com maior volume. Comparando-se os momentos, determinou-se queda na porcentagem de linfócitos e aumento na porcentagem de neutrófilos após o estresse.

A colina pode influenciar indiretamente a eritropoiese. Segundo Devlin (1997), vários derivados de um carbono do tetraidrofolato são utilizados em reações de biossíntese, como, por exemplo, para síntese de colina, serina, glicina, purinas e dTMP (timidina monofosfato). Segundo este autor, quando a quantidade de colina e de aminoácidos está adequada à síntese de purina e dTMP, parece ser metabolicamente mais significativa. Esses compostos são essenciais à síntese das células. Em quantidades inadequadas, pode haver atraso no processo de maturação dos glóbulos vermelhos, causando produção de células macrocíticas, o que pode levar ao processo de anemia.

Os valores apresentados pelos peixes alimentados com as dietas experimentais, na fase anterior ao estímulo a frio, estão dentro do considerado adequado para peixes sadios por Feldman et al. (2000) e Barros et al. (2006). Embora os peixes alimentados com a ração deficiente em colina apresentassem níveis normais de células vermelhas na fase anterior ao estímulo, esses animais foram os que apresentaram significativamente o menor número de células após o desafio. Entretanto, peixes alimentados com as dietas suplementadas com colina nos níveis de 200,0; 600,$0 ; 1.000,0$ e $1.200,0 \mathrm{mg} / \mathrm{kg}$ de ração também apresentaram baixa síntese de células vermelhas quando submetidos à baixa temperatura.

Isso demonstra que tanto a nutrição adequada quanto as condições de ambiente podem ter ação sobre a eritropoiese. Pickering (1981) classificou os principais agentes estressores em um sistema de produção de peixes como sendo: químicos (qualidade da água, poluição, composição da dieta e resíduos metabólicos), biológicos (densidade populacional, presença de outras espécies de peixes e de microrganismos), físicos (temperatura, luz, sons e gases dissolvidos) e de manejo (manuseio, transporte e tratamento de doenças). Considerando-se que o metabolismo dos peixes sofre influência direta da temperatura da água, esse fator tem sido considerado como o principal agente estressor quando fora da baixa de conforto da espécie. As principais consequências fisiológicas em condições de estresse para peixes são desequilíbrio iônico e osmótico (Mcdonald \& Milligan, 1997; Piiper, 1989) e alterações hematológicas (Mariano et al., 2006), hormonais, metabólicas (Moraes et al., 2004; Wendelaar Bonga, 1997) ena excreção dos produtos nitrogenados (Randall et al., 2004).

O prejuízo na manutenção dos parâmetros hematológicos dos peixes sob condições de baixa temperatura (estresse crônico) foi anteriormente descrito por Falcon et al. (2007), ao avaliarem a higidez de tilápiasdo-nilo alimentadas com dietas contendo suplementação de vitamina C e lipídeos, e por Signor (2007), também com tilápias-do-nilo alimentadas com níveis de levedura e zinco em rações práticas.

Tabela 3 - Leucócitos totais e proteína plasmática total de alevinos de tilápia-do-nilo alimentados com dietas suplementadas com colina e submetidos a estímulo por frio

\begin{tabular}{|c|c|c|c|c|}
\hline \multirow[b]{2}{*}{ Colina $^{1}$} & \multicolumn{2}{|c|}{ Leucócitos (mL) } & \multicolumn{2}{|c|}{ Proteína plasmática total (mg/dL) } \\
\hline & Fase $1^{2}$ & Fase $2^{3}$ & Fase $1^{2}$ & Fase $2^{3}$ \\
\hline 0,0 & $70750 \pm 17500 \mathrm{aA}$ & $48000 \pm 24500 \mathrm{aA}$ & $3,13 \pm 0,24 \mathrm{aB}$ & $2,48 \pm 0,31 \mathrm{aA}$ \\
\hline 100 & $68250 \pm 18250 \mathrm{aB}$ & $45750 \pm 9250 a A$ & $2,87 \pm 0,27 \mathrm{aB}$ & $2,25 \pm 0,29 a A$ \\
\hline 200 & $65750 \pm 41750 \mathrm{aA}$ & $54000 \pm 7000 \mathrm{aA}$ & $2,97 \pm 0,59 a \mathrm{~A}$ & $2,44 \pm 0,24 \mathrm{aA}$ \\
\hline 400 & $89000 \pm 33250 \mathrm{aB}$ & $44000 \pm 20750 \mathrm{aA}$ & $3,18 \pm 0,27 a A$ & $2,57 \pm 0,64 \mathrm{aA}$ \\
\hline 600 & $92000 \pm 60250 \mathrm{aA}$ & $47500 \pm 20500 \mathrm{aA}$ & $3,23 \pm 0,79 a A$ & $2,89 \pm 0,64 \mathrm{aA}$ \\
\hline 800 & $77250 \pm 51000 \mathrm{aA}$ & $44250 \pm 21000 \mathrm{aA}$ & $2,89 \pm 0,23 \mathrm{aA}$ & $2,47 \pm 0,29 \mathrm{aA}$ \\
\hline 1.000 & $76750 \pm 67000 \mathrm{aA}$ & $40500 \pm 17250 \mathrm{aA}$ & $3,15 \pm 0,25 a \mathrm{a}$ & $2,53 \pm 0,30 \mathrm{aA}$ \\
\hline 1200 & $71600 \pm 63000 \mathrm{aA}$ & $53750 \pm 16250 \mathrm{aA}$ & $3,06 \pm 0,54 \mathrm{aA}$ & $2,64 \pm 0,41 \mathrm{aA}$ \\
\hline
\end{tabular}

${ }^{1}$ Níveis de suplementação de colina em $\mathrm{mg} / \mathrm{kg}$ de dieta.

${ }^{2}$ Fase 1: antes do estímulo por frio.

3 Fase 2: após o estímulo por frio.

Letras minúsculas: comparação de níveis de colina fixado o momento.

Letras maiúsculas: comparação de momento dentro de tratamento. 
Quando os momentos foram comparados, a porcentagem de hematócrito, igualmente ao número de eritrócitos, estava abaixo dos valores normais para peixes sadios, para os alimentados com as rações suplementadas com 200,0, 400,0 e 1200,0 mg de colina/kg de ração, e para a taxa de hemoglobina nos peixes alimentados com a ração suplementada com 800,0 mg de colina/kg de ração. Nutricionalmente, não se encontrou embasamento para essa resposta, inferindo-se que tais resultados podem ter sido devido a outros fatores que não a suplementação de colina.

Segundo Tavares Dias \& Moraes (2004), há diferenças na resposta hemática à termoaclimatação, principalmente quando em baixas temperaturas, sendo que pode ocorrer processo de hemodiluição. Chen et al. (1995) ressaltaram que a hemodiluição pode determinar redução na biossíntese de hemoglobina e na eritropoiese. Embora não tenha sido observada alteração significativa na taxa de hemoglobina, houve decréscimo na produção de eritrócitos.

Na série branca, observou-se leucopenia nos peixes de todos os tratamentos, porém de modo significativo nos alimentados com a ração suplementada com 100,0 e 400,0 mg de colina $/ \mathrm{kg}$. Esse efeito foi anteriormente descrito por outros autores, e a não significância determinada na maioria dos tratamentos pode estar relacionada à grande variação na contagem das células. Essa queda no número de leucócitos foi acompanhada pelo decréscimo da porcentagem de linfócitos e pelo aumento da porcentagem de neutrófilos. Quadro de leucopenia, sob condições de estresse por temperatura, foi anteriormente descrito por Dunn et al. (1989) para Carassius auratus, e por Falcon et al. (2007) e por Signor (2007) para tilápias-do-nilo. O prejuízo ocasionado pelo estresse a frio às condições de higidez dos peixes fica evidente mesmo em condições nutricionais adequadas.

Comparando os momentos, observou-se queda na produção de proteína plasmática total, após o estresse, para os peixes alimentados com a ração ausente de suplementação de colina e nos peixes alimentados com a ração suplementada com 100,0 e 1.000,0 mg/kg (Tabela 4). Novamente, não houve tendência de resposta para o nível de suplementação. Esses resultados suportam a hipótese de que a temperatura de $17,0^{\circ} \mathrm{C}$ determina alterações fisiológicas que podem interferir no processo de defesa do peixe. Diminuição dos valores de proteínas plasmáticas totais após estímulo por baixa temperatura foi igualmente relatado por Falcon (2007). De forma oposta, Thomas (2000) relatou aumento das proteínas plasmáticas totais após estresse e processo de inflamação.

A não influência do nível de suplementação de colina na eritropoiese pode estar associada a quantidades adequadas de ácido fólico (tetraidrofolato) e ainda de vitamina $\mathrm{B}_{12}$ no suplemento vitamínico/mineral, o que estaria, portanto, suprindo a exigência nutricional de timidilato e, dessa forma, garantindo normal produção de células sanguíneas.

Tabela 4 - Número de linfócitos e mediana e semiamplitude de monócitos e neutrófilos de juvenil de tilápia-do-nilo alimentadas com dietas suplementadas com colina e submetidos a estímulo por frio

\begin{tabular}{|c|c|c|c|c|c|c|}
\hline \multirow[t]{2}{*}{ Colina $^{1}$} & \multicolumn{2}{|c|}{ Linfócitos (\%) } & \multicolumn{2}{|c|}{ Neutrócitos (\%) } & \multicolumn{2}{|c|}{ Monócitos (\%) } \\
\hline & Fase $1^{2}$ & Fase $2^{3}$ & Fase $1^{2}$ & Fase $2^{3}$ & Fase $1^{2}$ & Fase $2^{3}$ \\
\hline 0,0 & $92,75 \pm 1,17 \mathrm{aB}$ & $80,67 \pm 4,66$ abcA & $2,75 \pm 1,25 \mathrm{aA}$ & $15,25 \pm 4,50 \mathrm{bB}$ & $2,00 \pm 2,00 \mathrm{aA}$ & $3,50 \pm 2,25 \mathrm{aA}$ \\
\hline 100 & $91,08 \pm 5,76 a A$ & $89,83 \pm 4,57 \mathrm{cA}$ & $3,50 \pm 7,25 \mathrm{aA}$ & $8,00 \pm 4,25 \mathrm{aA}$ & $2,00 \pm 1,00 \mathrm{aA}$ & $2,00 \pm 0,75 \mathrm{aA}$ \\
\hline 200 & $92,67 \pm 2,93 \mathrm{aB}$ & $85,58 \pm 2,56 b c A$ & $3,00 \pm 1,50 \mathrm{aA}$ & $10,75 \pm 3,75 \mathrm{aB}$ & $2,00 \pm 1,25 \mathrm{aA}$ & $2,75 \pm 0,50 \mathrm{aA}$ \\
\hline 400 & $94,67 \pm 1,63 a B$ & $77,33 \pm 7,39 \mathrm{aA}$ & $1,25 \pm 1,00 \mathrm{aA}$ & $18,25 \pm 7,75 b B$ & $1,50 \pm 1,50 \mathrm{aA}$ & $3,50 \pm 1,50 \mathrm{aA}$ \\
\hline 600 & $91,67 \pm 1,44 \mathrm{aB}$ & $80,00 \pm 4,30 \mathrm{abA}$ & $4,75 \pm 2,25 \mathrm{aA}$ & $16,50 \pm 5,50 \mathrm{bB}$ & $2,75 \pm 1,50 \mathrm{aA}$ & $2,50 \pm 1,00 \mathrm{aA}$ \\
\hline 800 & $93,17 \pm 2,09 \mathrm{aB}$ & $83,33 \pm 4,62$ abc $A$ & $4,00 \pm 2,00 \mathrm{aA}$ & $12,50 \pm 5,25 \mathrm{abB}$ & $1,50 \pm 1,75 \mathrm{aA}$ & $2,00 \pm 1,00 \mathrm{aA}$ \\
\hline 1000 & $93,75 \pm 1,86 a B$ & $87,42 \pm 4,06 \mathrm{bcA}$ & $2,75 \pm 2,50 \mathrm{aA}$ & $8,75 \pm 4,50 \mathrm{aB}$ & $1,75 \pm 0,75 \mathrm{aA}$ & $2,50 \pm 1,00 \mathrm{aA}$ \\
\hline 1200 & $93,00 \pm 1,61 \mathrm{aB}$ & $81,17 \pm 8,98$ abcA & $3,75 \pm 2,25 \mathrm{aA}$ & $12,25 \pm 9,50 \mathrm{abB}$ & $2,25 \pm 1,00 \mathrm{aA}$ & $2,25 \pm 1,75 a$ \\
\hline
\end{tabular}

\footnotetext{
${ }^{1}$ Níveis de suplementação de colina em $\mathrm{mg} / \mathrm{kg}$ de dieta.

${ }^{2}$ Fase 1: antes do estímulo a frio.

${ }^{3}$ Fase 2: após o estímulo a frio.

Letras minúsculas: comparação de níveis de colina fixado o momento.

Letras maiúsculas: comparação de momento dentro de tratamento.
} 


\section{Conclusões}

A suplementação de colina não interfere na síntese de eritrócitos e leucócitos e a temperatura de $17,0^{\circ} \mathrm{C}$ proporciona linfopenia e neutrofilia.

\section{Referências}

ASSOCIATION OF OFFICIAL ANALYTICAL CHEMISTS AOAC. Official methods of analysis. 12.ed. Washington, 1975. 1094p.

BARROS, M.M.; PEZZATO, L.; FALCON, D.R. et al. Nutrição e saúde de peixes. In: CONGRESSO LATINO-AMERICANO DE NUTRIÇÃO ANIMAL, 2., 2006, São Paulo. Anais... São Paulo: Colégio Brasileiro de Nutrição Animal, 2006. (CD-ROM).

BOYD, C.E. Water quality in ponds for aquaculture. Songkhala: Shrimp Mart, 1996. 482p.

CHEN, G.R.; SUN, L.T.; LEE. Y.H. et al. Characterisitcs of blood in commom carp, Cyprinus carpio, exposed to low temperatures. Journal Applied Aquaculture, v.5, p.21-31, 1995.

COLLIER, H.B. The standardization of blood hemoglobin determinations. Canadian Medical Association Journal, v.50, p.550-552, 1944.

DEVLIN, T.M. Textbook of biochemistry with clinical correlations. New York: John Wiley \& Sons, Inc. Copyright. 1997. 1007p.

DEVLIN, T.M. Manual de bioquímica com correlações químicas. São Paulo: Edgard Blucher, 2000. 957p.

DUNN, S.E.; MURAD, A.; HOUSTON, A.H. Leucocyts and leucopoietic capacyt in thermally acclimated goldfish, Carassius auratus L. Journal Fish Biology, v.34, p.901-911, 1989.

FALCON, D.R. b-glucano e vitamina C na desempenho produtivo e parâmetros fisiopatológicos da tilápia-donilo: nível de suplementação e tempo de administração. 2007. 147f. (Doutorado em Aquicultura) - Universidade Estadual Paulista, Jaboticabal.

FELDMAN, B.F.; ZINKL, J.G.; JAIN, N.C. Schalm's veterinary hematology. 5.ed. Oxford: Blackwell Publishing Ltda, 2000. $1347 p$.

FURUYA, W.M.; PEZZATO, L.E.; BARROS, M.M. et al. Coeficientes de digestibilidade e valores de aminoácidos digestíveis de alguns ingredientes para tilápia do nilo (Oreochromis niloticus). Revista Brasileira de Zootecnia, v.30, n.4, p.1143-1149, 2001.

GOLDENFARD, P.B.; BOWYER, F.P.; HALL, E. et al. Reproducibility in the hematology laboratory: the microhematocrit determination. American Journal Clinic Path, v.56, n.1, p.35-39, 1971.

HALVER, E.J. Fish nutrition. San Diego: Academic Press, 1989. 693p.
JAIN, N.C. Schalm's veterinary hematology. 5.ed. Oxford: Blackwell Publishing Ltda., 2000. p.1120-1132.

JOHNSON, R.A.; WICHERN, D.W. Applied multivariate statistical analyses. 5.ed. New Jersey: Prentice-Hall, 2002. $767 p$.

MARIANO, W.S.; OBA, E.T.; SANTOS, L.R. et al. Respostas fisiológicas de jeju Hoplerythrinus unitaeniatus exposto ao ar atmosférico. Revista Brasileira de Saúde e Produção Animal, v.10, n.1, p.210-223, 2009.

McDONALD, G.; MILLIGAN, L. Ionic, osmotic and acid-base regulation. In: IWAMA, G.K.; PICKERING, A.D.; SUMPTER, J.P. et al. (Eds.) Fish stress and health in aquaculture. Cambridge: Cambridge University Press, 1997. p.119-144.

MORAES, G.; POLEZ, V.L.P.; IWAMA, G.K. Biochemical responses of two erythrinidae fish to environmental ammonia. Brazilian Journal of Biology. v.64, n.1, p.95-102, 2004.

NATIONAL RESEARCH COUNCIL - NRC. Nutrient requirements of fish. Washington, D.C.: National Academy Press, 1993. $124 \mathrm{p}$.

PEZZATO, L.E.; BARROS, M.M.; FURUYA, W.M. Valor nutritivo dos alimentos utilizados na formulação de rações para peixes tropicais. Revista Brasileira de Zootecnia, v.38, p.43-51, 2009 (supl. especial).

PICKERING, A.D. Introduction: the concept of biological stress. In: PICKERING, A.D. (Ed.) Stress and fish. London: Academic Press, 1981. p.1-9.

PIIPER, J. Factors affecting gas transfer in respiratory organs of vertebrates. Canadian Journal of Zoology, v.67, n.1, p.2956-2960, 1989.

RANDALL, D.J.; IP, Y.K.; CHEW, S.F. et al. Air breathing and ammonia excretion in the giant mudskipper, Periophthalmus schlosseri. Physiological and biochemical Zoology, v.77, n.5, p.783-788, 2004.

RANZANI-PAIVA, M.J.T.; SILVA-SOUZA, A.T. Hematologia de peixes brasileiros. Sanidade de organismos aquáticos. São Paulo: Varela, 2004. p.89-120.

SIGNOR, A. Desempenho produtivo e resistência ao estresse a frio da tilápia-do-nilo Oreochromis niloticus submetidas a dietas contendo levedura autolisada e zinco. 2007. 103f. (Mestre em Aquicultura) - Universidade Estadual Paulista, Jaboticabal.

TAVARES-DIAS, M.; MORAES, F.R. Hematologia de peixes teleósteos. Ribeirão Preto: Willimpress Complexo Gráfico, 2004. 144p.

THOMAS, J.S. Overview of plasma proteins. In: FELDMAN, B.F.; ZINKL, J.G.; JAIN, N.C. (Eds.) Schalm's veterinary hematology. 5.ed. Oxford. Blackwell Publishing Ltda., 2000. p.891-898.

WendelaAR BOnga, S.E. The stress response in fish. Physiol, v.77, p.591-625, 1997.

WINTROBE, M.M. Variations in the size and hemoglobin content of erythrocytes in the blood of various vertebrates. Folia Haematologica, v.51, p.32-49, 1934. 